\title{
A REDE URBANA DA REGIÃO DOS VALES - RS: O PAPEL DAS CIDADES MÉDIAS DE SANTA CRUZ DO SUL E LAJEADO
}

\author{
FACCIN, C. R. 1; GIACOMETTI, N. B.2; SILVEIRA, R. L. L.3; BRANDT, G. B.4.
}

PALAVRAS CHAVE: Rede urbana. Cidades médias. Fluxo de pessoas. Região dos Vales-RS.

\section{RESUMO}

A dinâmica da rede urbana regional e a importância de suas cidades médias podem ser analisadas através de distintos elementos e fluxos no território. Um deles decorre da dinâmica populacional regional. Desse modo, pretende-se analisar a importância e o poder de centralização e de articulação das cidades médias de Santa Cruz do Sul e de Lajeado no território da Região dos Vales, no estado do Rio Grande do Sul, através de dados relativos a fluxos de pessoas. Também pretende-se analisar o papel dessas cidades médias para o equilíbrio da rede urbana regional, verificando se elas atraem investimentos e mão de obra para si e para os demais municípios da sua região de influência e da rede urbana regional, ou se estão concentrando os investimentos e a população regional. Para isso, foram utilizados dados do Censo Demográfico de 1991, 2000 e 2010, além de dados da pesquisa Regiões de Influência das Cidades (REGIC), de 2007, elaborados pelo IBGE. Os dados coletados confirmam a centralidade de Santa Cruz do Sul e Lajeado e evidenciam uma situação de crescimento desequilibrado da rede urbana regional.

\section{THE URBAN NETWORK OF THE REGIÃO DOS VALES: THE ROLE OF THE INTERMEDIATES CITIES OF SANTA CRUZ DO SUL AND LAJEADO}

KEYWORDS: Urban Network. Intermediate cities. Flows of people. Região dos Vales-RS.

\begin{abstract}
A regional urban network dynamic and the importance of its intermediate cities can be analyzed through distinct elements and flows in the territory. One of them derives from the regional population dynamics. In this way, we intend to analyze the importance and the power of articulation of the intermediate cities of Santa Cruz do Sul and Lajeado in the territory of the Região dos Vales, in the state of Rio Grande do Sul, through data related to flows of people. It is also intended to evaluate the role of these cities in the balance of the regional urban network, verifying whether they attract investment and manpower for themselves and for the other municipalities in their region of influence and their regional urban network, or if they concentrate the investments and the population of their region. For that, data from the 1991, 2000 and 2010 Demographic Census were used, as well as data from the 2007 study Regions of Influence of Cities (REGIC), organized by IBGE. The data collected confirm the centrality of Santa Cruz do Sul and Lajeado and show a situation of unbalanced growth of the regional urban network.
\end{abstract}

\footnotetext{
1 Graduada em Arquitetura e Urbanismo pela Universidade de Santa Cruz do Sul.

2 Estudante de Arquitetura e Urbanismo na Universidade de Santa Cruz do Sul.

${ }^{3}$ Docente do Programa de Pós-Graduação em Desenvolvimento Regional e do Departamento de História e Geografia na Universidade de Santa Cruz do Sul.

${ }_{4}^{4}$ Docente do Programa de Pós-Graduação em Desenvolvimento Regional e do Departamento de Comunicação Social na Universidade de Santa Cruz do Sul.
} 


\section{INTRODUÇÃO}

Os estudos sobre desenvolvimento urbano e regional têm valorizado a rede urbana, seja como recurso metodológico para a compreensão do dinamismo socioespacial e econômico intra e interregional em sua expressão territorial, ou seja, como estratégia de promoção de políticas públicas de desenvolvimento territorial. Eles têm sido amplamente realizados no contexto da União Europeia, onde busca-se estimular o desenvolvimento de redes urbanas policêntricas. Exemplos disso são os estudos realizados pelo ESPON (2004), Davoudi (2003) e Cattan (2007), no âmbito da União Europeia, por Pillet et. Al (2010) na região de Castilla-La Mancha, na Espanha, e por Sýkora e Muliček (2009) na República Tcheca.

Uma rede urbana é constituída por um conjunto hierárquico de cidades funcionalmente articuladas entre si. Ou seja, os nós da rede são as cidades que, dotadas de distintas funções urbanas, a partir das suas respectivas dinâmicas produtivas e especializações econômicas, se interligam pelo sistema de infraestruturas viárias e de comunicação e, possibilitam a conexão e a circulação de diversos fluxos entre essas cidades, e entre elas as demais localidades e espaços das regiões (CORRÊA, 2006).

É nesse contexto que se destacam as cidades médias. Estas, por sua vez, só podem ser compreendidas como parte integrante de uma rede urbana, uma vez que são de natureza relacional e envolvem relações com centros menores e maiores do que elas. Elas possuem papel estratégico na rede urbana por serem referência para pequenos aglomerados urbanos e o meio rural de seu entorno, intermediando fluxos com centros urbanos maiores e mais importantes hierarquicamente. Sendo assim, são importantes nós de redes urbanas em diferentes escalas regionais (CORRÊA, 2017; BRANCO, 2006).

Assim, uma rede urbana regional e suas cidades médias, podem ser analisadas, mesmo que parcialmente, a partir da sua dinâmica populacional. Esta dinamicidade pode ocorrer tanto como consequência das relações econômicas e sociais que se estabelecem em um determinado espaço, ou ainda, podem ser estimuladas através de movimentos migratórios. Parte-se desse princípio para analisar a importância e o poder de articulação de duas cidades médias da Região dos Vales, no Rio Grande do Sul, através de dados relativos aos fluxos de pessoas. Também, pretende-se analisar se estas cidades auxiliam no equilíbrio da rede urbana regional, servindo como polos de desenvolvimento ou se concentram os investimentos e a população da região.

Assim, partiremos da caraterização da Região dos Vales para definir e justificar a escolha das cidades médias a serem estudadas. A Região dos Vales está localizada no centro do Rio Grande do Sul, Brasil e, constituise em uma região funcional de planejamento criada pelo governo gaúcho, em 2006. Essa região é constituída pelas sub-regiões contíguas do Vale do Rio Pardo e do Vale do Taquari. Com base no estudo de Ramos, Matos e Garcia (2011), buscamos analisar o papel das cidades médias de Santa Cruz do Sul e Lajeado em suas respectivas áreas de influência, definidas pelas Regiões de Influência (REGIC) de 2007 elaborado pelo IBGE, com o objetivo de verificar o papel dessas cidades médias para o equilíbrio da rede urbana regional, analisando se elas atraem investimentos e mão de obra para si e para os demais municípios da sua região de influência e da rede urbana regional ou se estão concentrando os investimentos e a população regional. Ou seja, busca-se confirmar ou não, a hipótese da hierarquia urbana da rede urbana e da intensidade da polarização que as cidades médias exercem sobre os municípios da região.

Conforme Ramos, Matos e Garcia (2011, p. 47):

É provável que um processo de maior concentração de população em algumas das centralidades analisadas esteja em curso, em detrimento dos municípios menos dinâmicos, portanto, com menor capacidade de 
atrair e/ou reter população. Também é possível que isto não esteja acontecendo ou que os municípios menores estejam crescendo junto com o município-polo.

Este artigo apresenta alguns dos resultados parciais do projeto de pesquisa "Policentrismo e desenvolvimento regional no Rio Grande do Sul: Uma análise do papel das cidades médias e da rede urbana nos processos de coesão e desenvolvimento territorial", em andamento e financiado pelo Conselho Nacional de Desenvolvimento Científico e Tecnológico (CNPq) e pela Fundação de amparo à Pesquisa do Estado do Rio Grande do Sul (FAPERGS). 0 projeto está sendo desenvolvido no âmbito do Grupo de Pesquisa Estudos Urbanos e Regionais (GEPEUR), sendo este vinculado ao Programa de Pós-Graduação em Desenvolvimento Regional, da Universidade de Santa Cruz do Sul (PPGDR - UNISC) e ao CNPq.

Após esta introdução, discorremos brevemente sobre os conceitos de rede urbana e de cidade média. Em seguida, apresentamos a metodologia utilizada para a realização desta análise. Após, segue-se uma breve caracterização espacial e socioeconômica da Região dos Vales e das suas cidades médias: Santa Cruz do Sul e Lajeado, seguindo da análise dos dados coletados. Por fim, encerramos com as considerações finais.

\title{
2 FUNDAMENTAÇÃO TEÓRICA
}

\subsection{REDE URBANA}

A rede urbana, conforme Corrêa (2017, p. 29) "é entendida como o conjunto de centros, hierarquizados ou funcionalmente especializados e com diversas dimensões demográficas, articulados entre si, via fluxos materiais e não materiais". Ela é um reflexo e uma condição da divisão territorial do trabalho, enquanto conjunto articulado de cidades, de diferentes portes e funções. Estas cidades, articuladas através de fluxos de diversos tipos, materiais e imateriais, estruturam e organizam o território da região (CORRÊA, 1989).

Conforme Corrêa (1989, p. 6-7), admitimos a existência de uma rede urbana quando, no mínimo, são satisfeitas as seguintes condições:

\begin{abstract}
Primeiramente, haver uma economia de mercado com uma produção que é negociada por outra que não é produzida local ou regionalmente. Esta condição tem como pressuposto um grau mínimo de divisão territorial do trabalho. Em segundo lugar, verificar-se a existência de pontos fixos no território onde os negócios acima referidos são realizados, ainda que com certa periodicidade e não de modo contínuo. (...) A terceira condição refere-se ao fato da existência de um mínimo de articulação entre os núcleos anteriormente referidos, articulação que se verifica no âmbito da circulação, etapa necessária para que a produção exportada e importada se realize plenamente, atingindo os mercados consumidores.
\end{abstract}

No Brasil, Roberto Lobato Corrêa e Milton Santos muito contribuíram na discussão sobre a temática acerca da rede urbana, sobretudo nos anos de 1960, 1970 e início de 1990, analisando a rede urbana brasileira e suas metamorfoses, diante das transformações estruturais que ocorreram no país a partir de meados do século XX (RODRIGUES; SILVA, 2007). Além disso, em âmbito nacional, diversas pesquisas estudam o comportamento da rede urbana. Destacam-se, principalmente, aquelas desenvolvidas pelo Instituto Brasileiro de Geografia e Estatística (IBGE), denominadas de Região de Influência das Cidades (REGIC). Em nível regional ou estadual, existem ainda outros estudos, como é o caso de alguns desenvolvidos pelo Instituto de Pesquisa Econômica Aplicada (IPEA).

Estudos como os da REGIC carregam uma tradição que remonta à teoria dos lugares centrais de Christaller, cujo núcleo está na ideia de centralidade que, por sua vez, deriva das funções da cidade. Olhando 
atentamente, além da hierarquia, a riqueza desses estudos está no fato de revelarem arranjos territoriais distantes da narrativa metropolitana, especialmente em países com as dimensões territoriais do Brasil (ARRAIS, 2008).

No atual cenário global, a globalização tem sido responsável por um aumento das interações entre as cidades e pela formação de novas redes urbanas, com o objetivo de tornar, os territórios mais competitivos e complementares. Nesse contexto, as redes urbanas também estão muito associadas ao desenvolvimento de complementaridades entre as cidades. Assim, várias cidades da rede desempenham funções diferentes, mas que incidem mutuamente para o desenvolvimento da região (FONSECA; RAMOS, 2011).

Assim, a dinâmica de funcionamento da rede urbana promove a integração espacial e econômica, seja entre a cidade e o campo, seja entre cidades médias e metrópoles para com suas regiões de influência. Regiões essas, que podem ser definidas pela amplitude e complexidade dos fluxos que tais cidades atraem e comandam no território. Dessa forma, pode-se pensar nas redes urbanas como possibilidade de, através delas, se criar e desenvolver políticas de integração e complementariedade funcional, e de promover projetos de cooperação entre as cidades. Tais políticas e projetos ao valorizarem as particularidades territoriais e efetivarem as potencialidades locais e regionais, bem como a competitividade e a inovação, poderão contribuir para promover a coesão territorial e o desenvolvimento regional na escala regional (SILVEIRA, 2018).

\subsection{CIDADE MÉDIA}

No Brasil, conforme Corrêa (2006), a noção de cidade média remonta à década de 1960, no âmbito do recém-criado sistema de planejamento, que pretendia incluir a dimensão espacial nas políticas governamentais. Assim, estabeleceu-se a noção "cidade de porte médio", com o intuito de utilizá-las como barreiras receptoras contra as correntes migratórias em direção aos centros metropolitanos. Porém, o termo tem ganhado força nos últimos anos, conforme Andrade e Serra (1998), graças aos processos de redistribuição espacial da população brasileira e de reversão da polarização industrial.

Em Stamm et al. (2013), foi analisada a dispersão da população urbana e a difusão das cidades de porte médio no Brasil entre as décadas de 1970 e 2010. A partir desta análise, observou-se um aumento do número de cidades de porte médio, ocorrendo um processo de desconcentração populacional das grandes metrópoles nacionais. Destaca-se o crescimento expressivo das cidades de porte médio não metropolitanas, enquanto as metropolitanas cresceram, mas não tão expressivamente.

Cabe salientar que o grande responsável pela dispersão espacial da população foi à tendência à desconcentração industrial, ocorrida entre 1970 e 1990; a mobilidade da fronteira agrícola, estimulada pela modernização da agricultura, e a transferência de excedentes populacionais das zonas rurais; e os investimentos em infraestrutura, que integraram o interior do Brasil à dinâmica da economia nacional (STAMM et al., 2013, p. 263).

Assim, as cidades médias são vistas pelas políticas de desenvolvimento territorial como núcleos com intensa centralidade e com uma grande capacidade de organização do território. Os discursos oficiais governamentais referem-se às potencialidades desse tipo de centro objetivando modelos territoriais mais equilibrados, através do policentrismo, do desenvolvimento local e de sistemas urbanos equilibrados (SANFELIU, 2017). 
Porém, quanto ao seu termo, carece de uma definição mais precisa. Termos como cidade intermediária, cidade regional, cidade de porte médio ou centro regional, também são utilizados como sinônimos, sem grande precisão (OLIVEIRA; SOARES, 2014).

De forma geral, a cidade média tem como principal critério para sua definição o quantitativo populacional (DEUS, 2004). Entretanto, diferentes instituições possuem diferentes classificações, como mostra a Tabela 1. Pelos critérios da ONU (Organização das Nações Unidas), as cidades médias estão agrupadas em aglomerações urbanas com população de 100 mil a um milhão de habitantes. De forma a comparar, na União Europeia (UE), são classificadas como "médias" as cidades de $\mathbf{2 5 0}$ mil a 500 mil habitantes. Com relação ao Brasil, segundo os critérios oficiais formulados pelo IBGE, são consideradas cidades médias as unidades urbanas com população entre 100 e 500 mil habitantes. Ou seja, em diferentes escalas e em diferentes localidades, a faixa populacional se altera. 0 que no Brasil poderia ser considerado uma cidade grande, em escala mundial, e de acordo com a $\mathrm{ONU}$, seria considerado uma cidade média. 0 mesmo ocorre em comparação à União Europeia: o que na UE poderia ser uma cidade pequena, no Brasil já poderia ser considerado uma cidade média.

Tabela 1. Definição de cidades, de acordo com o tamanho populacional, por diferentes instituições.

\begin{tabular}{|c|c|c|c|}
\hline $\begin{array}{l}\text { Definição de } \\
\text { cidades }\end{array}$ & ONU & União Europeia & IBGE \\
\hline Cidade pequena & $\begin{array}{l}\text { Menos de } 100.000 \\
\text { hab. }\end{array}$ & $\begin{array}{l}\text { Menos de } 250.000 \\
\text { hab. }\end{array}$ & $\begin{array}{l}\text { Menos de } 100.000 \\
\text { hab. }\end{array}$ \\
\hline Cidade média & $\begin{array}{l}\text { De } 100.000 \text { hab. a } \\
1.000 .000 \text { hab. }\end{array}$ & $\begin{array}{l}\text { De } 250.000 \text { hab. a } \\
500.000 \text { hab. }\end{array}$ & $\begin{array}{l}\text { De } 100.000 \text { a } \\
500.000 \text { hab. }\end{array}$ \\
\hline Cidade grande & $\begin{array}{l}\text { Mais de } 1.000 .000 \\
\text { hab. }\end{array}$ & $\begin{array}{l}\text { Mais de } 500.000 \\
\text { hab. }\end{array}$ & $\begin{array}{l}\text { Mais de } 500.000 \\
\text { hab. }\end{array}$ \\
\hline Metrópole & $\begin{array}{l}\text { Mais de } \\
10.000 .000 \text { hab. }\end{array}$ & $\begin{array}{l}\text { Mais de } 1.000 .000 \\
\text { hab. }\end{array}$ & $\begin{array}{l}\text { Mais de } 1.000 .000 \\
\text { hab. }\end{array}$ \\
\hline
\end{tabular}

Fonte: Carolina Faccin (2019), adaptado de SANFELIU (2017).

De todo modo, pensamos que sua definição não deva estar apenas vinculada ao tamanho da sua população. Segundo Branco (2006, p. 2), "a definição de cidades intermediárias não se vincula apenas a classificação por porte populacional. Relaciona-se também às suas funções e, principalmente, ao papel que desempenham na rede urbana regional, nacional e internacional". Além disso, Soares (2005) afirma que mesmo identificada como médias, cada cidade possui sua singularidade, com diferentes formas de relações na rede urbana e, principalmente com seu entorno regional, especialmente com as cidades pequenas e o campo. Sendo assim, as cidades médias podem ser entendidas como cidades com uma população acima da média regional, que exercem uma influência em uma determinada sub-região, com funções que a fazem assumir o papel de polo regional na hierarquia urbana, provendo o consumo produtivo e coletivo da sub-região onde está inserida (DEUS, 2004).

Tendo isso em vista, e não sendo entendidas como pontos isolados na rede urbana, as cidades médias têm aparecido nos estudos recentes da urbanização como importantes pontos na rede (SOARES, 2005), tornando necessário o entendimento do papel que essas cidades ocupam na rede urbana e no sistema econômico global. Para isso, é necessário que se considere as relações estabelecidas tanto em nível local como em nacional ou internacional (OLIVEIRA, SOARES, 2014).

Por conta disso, os estudos da REGIC elaborados pelo IBGE em 1966, 1978, 1993 e 2007, se mostram tão importantes. Esses estudos valorizam o papel das cidades médias como centros de intermediação e 
identificam a hierarquia de cada uma das cidades dentro do território nacional. Além disso, a riqueza desses estudos está no fato de revelarem arranjos territoriais distantes da narrativa metropolitana, o que se mostra especialmente necessário em países com as dimensões territoriais do Brasil.

Diante desse quadro, deve-se estudar as cidades médias considerando as possibilidades de circulação de pessoas, mercadorias, informações e valores, já que são esses elementos que intensificam as relações entre as cidades e suas regiões e, ao mesmo tempo, as fazem diferentes umas das outras (SOARES, 2005). Sendo assim, para este trabalho, consideraremos os fluxos de pessoas para analisar as cidades médias de Santa Cruz do Sul e Lajeado com relação à suas regiões de influência.

\section{MATERIAIS E MÉTODOS}

A construção desta análise sobre a importância das cidades médias de Santa Cruz do Sul e Lajeado em suas regiões de influência, envolveu determinados procedimentos metodológicos. A primeira etapa consistiu inicialmente de uma revisão teórica e conceitual, por meio de pesquisa bibliográfica, para delimitar os conceitos de rede urbana e cidade média.

Em um segundo passo metodológico, foi realizada uma breve caracterização espacial e socioeconômica da Região dos Vales (definida como aquela que espacialmente engloba conjuntamente as delimitações políticas dos Conselhos Regionais de Desenvolvimento (COREDEs) do Vale do Rio Pardo e Taquari), analisando a estrutura e configuração espacial dos sistemas viários e de transportes existentes, em sua relação com a dinâmica da rede urbana. Tendo feito isso, foram definidas quais seriam as cidades médias a serem estudadas da Região dos Vales e quais eram suas regiões de influência, através das bases de dados dos estudos das Regiões de Influência das Cidades - REGIC (2007), (IBGE, 2008).

Em um terceiro passo, foram utilizados dados referentes à dinâmica populacional da região, através dos dados secundários do Censo Demográfico (1991, 2000 e 2010), levantado pelo IBGE. Utilizou-se dados relativos aos deslocamentos pendulares para trabalho e estudo, destacando os fluxos acima de $10 \%$. Também se buscou dados acerca do crescimento populacional de 1991 a 2000, e de 2000 a 2010, bem como a taxa líquida de migração, ou seja, o impacto do saldo migratório sobre a população total. Após, buscou-se formar indicadores de desenvolvimento econômico, através da coleta de dados referentes ao Produto Interno Bruto (PIB) dos municípios.

Por fim, realizou-se o tratamento e análise dos dados através da confecção de gráficos, tabelas e mapas temáticos. Enquanto as tabelas foram configuradas e organizadas em softwares de edição de planilhas, como o Excel, os mapas temáticos foram elaborados através do uso de shapefiles disponibilizados pelo IBGE, editados em programas de georreferenciamento como o QGis e finalizados livremente em programas de tratamento de imagens vetorizadas, como o Adobe Illustrator. A análise e crítica dos resultados obtidos foi realizada com base no referencial teórico e conceitual adotado nessa pesquisa.

\section{RESULTADOS E DISCUSSÕES}

A Região dos Vales, localizada na zona centro oriental do Estado do Rio Grande do Sul, corresponde a Região Funcional de Planejamento dois do Governo Estadual e, é a junção das Regiões dos COREDEs do Vale do Rio Pardo e do Vale do Taquari. De acordo com IBGE (2010), a região possuía população o total de 745.864 
habitantes, o equivalente a $7 \%$ da população do estado. Daquele total, $68 \%$ da população residem na área urbana e 32\% na área rural. Apesar disso, dos 59 municípios da região, 35 apresentam mais de $50 \%$ da população residindo no meio rural, tendo, portanto, municípios predominantemente rurais. Entre os municípios que integram a região, destacam-se Santa Cruz do Sul e Lajeado, com os maiores e principais centros urbanos da região, cada um com, respectivamente, 118.374 e 71.445 habitantes, em 2010. Já em 2018, o IBGE (2018), estimou que esses dois municípios possuíssem, respectivamente, 129.427 e 82.951 habitantes. Além disso, os dados do PIB municipal, em 2010, para a região, evidenciam o destaque das cidades de Santa Cruz do Sul (R\$ 4.178.595 mil), Lajeado (R\$ 2.124.294 mil) e Venâncio Aires (R\$1.724.270 mil) (IBGE, 2010).

Com relação à estrutura econômica da região, o setor produtivo mais tradicional destaca as atividades de base agrícola, fundada em quatro produtos dominantes - fumo, milho, arroz e soja - com produção quase toda sustentada por pequenas propriedades rurais. No Vale do Rio Pardo, os principais segmentos são os produtos do fumo e o abate e fabricação de produtos de carnes. Já o Vale do Taquari apresenta uma estrutura industrial mais diversificada, com destaque para o abate e fabricação de produtos de carne, a fabricação de produtos de madeira e a preparação de couro e artefatos de couro (SEPLAN, 2015).

Nas cidades médias de Santa Cruz do Sul e de Lajeado a economia urbana se estrutura através do beneficiamento agroindustrial de produtos como o tabaco e da carne de aves e suínos, com a presença hegemônica de subsidiárias multinacionais. Há também, a participação destacada de empresas locais ligadas aos setores de alimentos, de metalomecânica, metalurgia, de artefatos de borracha e de empresas e instituições privadas relacionadas ao desenvolvimento do setor de comércio e serviços. Bem como, destacam-se os setores da saúde e da educação superior; e dos serviços relacionados ao setor público, diante da existência, nessas cidades, de inúmeras repartições de diversos órgãos públicos federais e estaduais, seja do poder executivo, quanto do judiciário.

Nessa estrutura urbana regional, as cidades de Santa Cruz do Sul e Lajeado se destacam como principais núcleos urbanos, polarizando e exercendo sua influência no espaço regional, através da concentração de grande parte das empresas industriais e de serviços que integram a divisão territorial do trabalho regional. Os dados da REGIC (2007), reforçam isso, identificando nessas duas cidades a mais alta hierarquia urbana da rede urbana da Região dos Vales. Ambas são classificadas como Centro Sub-regional A. Num nível hierárquico abaixo, como Centro de Zona A, tem-se as cidades de Venâncio Aires, Estrela e Encantado, e em um terceiro nível, como Centro de Zona B, tem-se as cidades de Arvorezinha, Sinimbu, Teutônia, Arroio do Meio e Muçum.

A Figura 1 apresenta a espacialização desses dados relativos às REGIC's de Santa Cruz do Sul e de Lajeado, definidas como cidades médias no âmbito da Região dos Vales, por intermediarem fluxos entre a metrópole de Porto Alegre e os municípios menores de seus entornos. Além disso, Santa Cruz do Sul não influencia diretamente Mato Leitão e Herveiras, sendo que esses fluxos são intermediados respectivamente por Venâncio Aires e Sinimbu. Apesar disso, todos esses municípios fazem parte da região de influência de Santa Cruz do Sul e Lajeado (IBGE, 2008). 
Figura 1. A área de influência de Santa Cruz do Sul e Lajeado conforme a REGIC (2007).

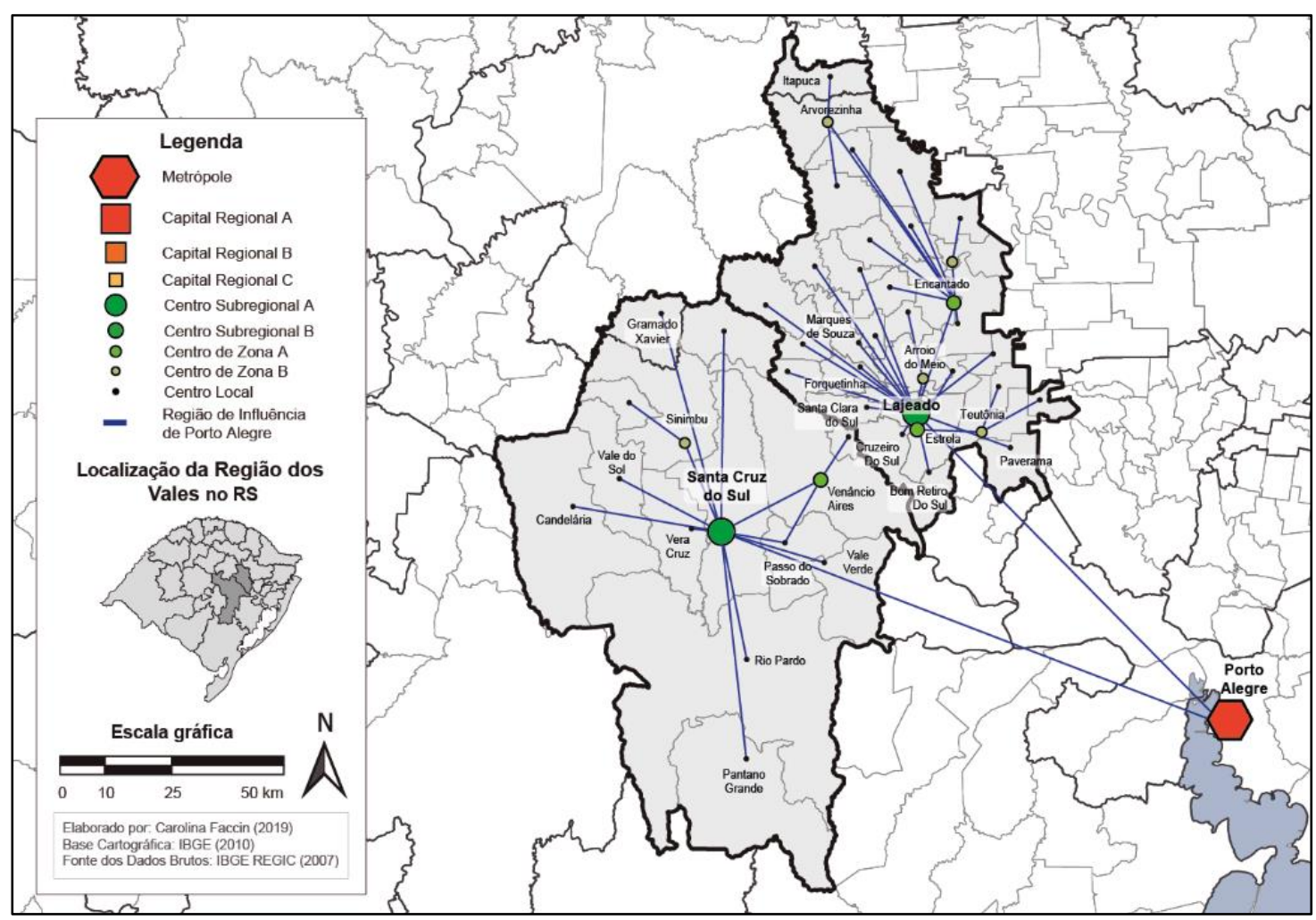

Fonte: Carolina Faccin, a partir de IBGE (2008).

Já a Figura 2 apresenta os principais eixos rodoviários e a densidade demográfica de acordo com a Grade Estatística, elaborada pelo IBGE (IBGE, 2016a). Em relação aos principais eixos rodoviários, pode-se destacar a BRS-287, que liga Lajeado a Santa Cruz do Sul; a BR-386, que conecta Lajeado a uma das principais artérias de circulação do Estado; e a BR-471, que faz importante ligação dos municípios do Vale do Rio Pardo com o município de Rio Grande e o extremo sul do Estado. Estas rodovias recebem intenso tráfego de mercadorias e passageiros de outras regiões, até de países vizinhos e aproximam a Região dos Vales, da Região Metropolitana de Porto Alegre (RMPA), conectam as cidades médias de Santa Cruz do Sul e de Lajeado à capital gaúcha e ao centro regional de Caxias do Sul. Há igualmente ligações da região com o interior do Estado, notadamente com as áreas de influência de Passo Fundo, no norte, e de Santa Maria, no oeste da região (SEPLAN, 2015).

A Figura 2 igualmente permite observar que a proximidade espacial e a acessibilidade viabilizada por essas rodovias possibilita a existência de um tempo e deslocamento relativamente curto, entre a cidade de Santa Cruz do Sul e as cidades de Vera Cruz (10 minutos), Candelária, Rio Pardo e Venâncio Aires (30 minutos), e menor ainda entre a cidade de Lajeado e as cidades de Estrela, Arroio do Meio e Cruzeiro do Sul (5 minutos), evidenciando a existência de um aglomerado urbano expressivo.

Em relação à densidade demográfica, constata-se maiores aglomerações de pessoas na região de influência de Lajeado, em comparação à região de Santa Cruz do Sul. Enquanto a primeira possui densidade de $66,1 \mathrm{hab} / \mathrm{km}^{2}$, e $4.432,67 \mathrm{~km}^{2}$ de área territorial, a segunda possui 43,0 hab/ $\mathrm{km}^{2}$ e 7.786,10 km² de área. Destaca-se a contiguidade dos centros urbanos dos municípios de Vera Cruz e Santa Cruz do Sul; de Lajeado, Estrela, Cruzeiro do Sul, Arroio do Meio e Santa Clara do Sul; e de Encantado, Roca Sales e Muçum (IBGE, 2010). 
Também na Figura 2 pode-se observar uma maior fragmentação territorial dos municípios que constituem a região de influência de Lajeado, em comparação à região de influência de Santa Cruz do Sul. Enquanto a primeira possui 33 municípios e área territorial de 4.432,7 $\mathrm{km}^{2}$, a segunda possui 14 municípios e uma área de $7.786,1 \mathrm{~km}^{2}$. Essa maior fragmentação municipal pode ser explicada devido a um intenso processo de emancipações municipais ocorrido entre os anos 1988 e 2001.

Figura 2. Tempo de deslocamento a partir das cidades de Santa Cruz do Sul e Lajeado.

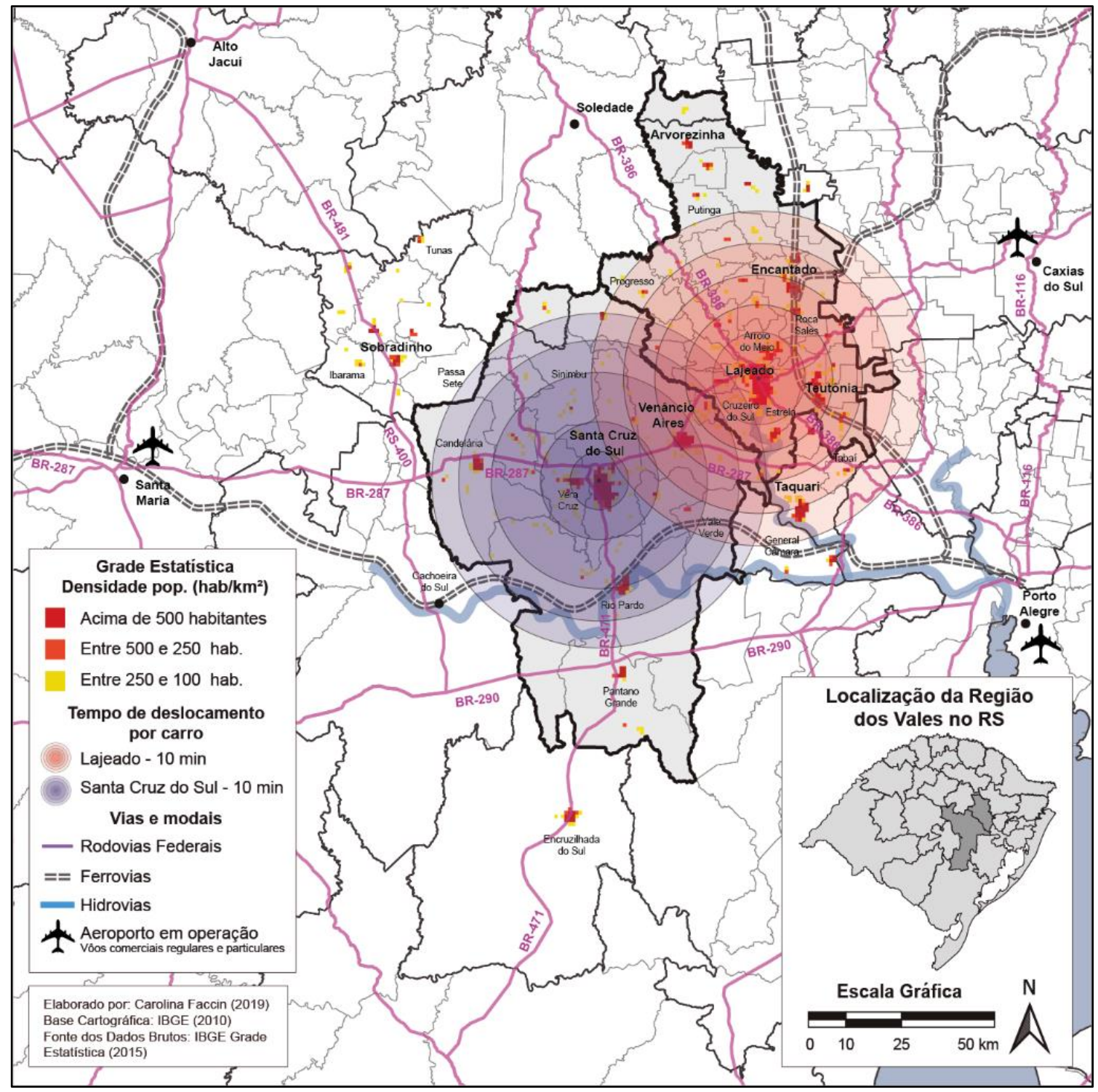

Fonte: Carolina Faccin, a partir de IBGE (2016a).

Além disso, a região de influência de Lajeado apesar de ter uma maior densidade demográfica, dos 33 municípios que a integram, 24 possuem menos de 10 mil habitantes e, destes, 20 municípios apresentam menos de cinco mil habitantes (Tabela 2). 
Tabela 2. Região de Influência de Lajeado: $N^{\circ}$ de cidades por faixa de população (2010).

\begin{tabular}{cccccc}
\hline $\begin{array}{c}\text { Até } 5 \text { mil } \\
\text { habitantes. }\end{array}$ & $\begin{array}{c}\text { De } 5.001 \mathrm{a} \\
10.000 \text { hab. }\end{array}$ & $\begin{array}{c}10.001 \mathrm{a} \\
20.000 \text { hab. }\end{array}$ & $\begin{array}{c}20.001 \mathrm{a} \\
50.000 \text { hab. }\end{array}$ & $\begin{array}{c}50.001 \mathrm{a} \\
100.000 \text { hab. }\end{array}$ & $\begin{array}{c}\text { Mais de } \\
100.001 \text { hab. }\end{array}$ \\
\hline 20 & 4 & 5 & 3 & 1 & 0 \\
\hline
\end{tabular}

Fonte: Carolina Faccin, a partir de IBGE (2010).

De forma semelhante, a região de influência de Santa Cruz do Sul possui sete, dos seus 14 municípios, com população inferior a 10 mil habitantes (Tabela 3). Ainda, ao agregar os municípios conforme o tamanho de população observa-se que, dentro da região de influência de Santa Cruz do Sul, os dois mais populosos municípios (Santa Cruz do Sul e Venâncio Aires) concentram mais da metade da população da REGIC de Santa Cruz do Sul (55\%). Enquanto, na REGIC de Lajeado, os quatro maiores municípios (Lajeado, Estrela, Teutônia e Encantado), concentram $51 \%$ da população da Regic de Lajeado.

Tabela 3. Região de Influência de Santa Cruz do Sul: Nº de cidades por faixa de população (2010).

\begin{tabular}{cccccc}
\hline $\begin{array}{c}\text { Até } 5 \text { mil } \\
\text { habitantes. }\end{array}$ & $\begin{array}{c}\text { De } 5.001 \mathrm{a} \\
10.000 \text { hab. }\end{array}$ & $\begin{array}{c}10.001 \mathrm{a} \\
20.000 \text { hab. }\end{array}$ & $\begin{array}{c}20.001 \mathrm{a} \\
50.000 \text { hab. }\end{array}$ & $\begin{array}{c}50.001 \mathrm{a} \\
100.000 \text { hab. }\end{array}$ & $\begin{array}{c}\text { Mais de } \\
100.001 \text { hab. }\end{array}$ \\
\hline 4 & 3 & 2 & 3 & 1 & 1 \\
\hline
\end{tabular}

Fonte: Carolina Faccin, a partir de IBGE (2010).

Esses dados, em conjunto com a Figura 3, explicitam uma dinâmica simples de funcionamento, de ambas as redes urbanas, com uma simplificada estrutura morfológica e limitada divisão territorial do trabalho. A Figura 3 representa espacialmente os deslocamentos pendulares para trabalho e estudo, da População Economicamente Ativa (PEA), entre os municípios da região de influência de Santa Cruz do Sul e Lajeado.

Figura 3. Deslocamentos pendulares da PEA, para trabalho e estudo, para Santa Cruz do Sul e Lajeado (\%).

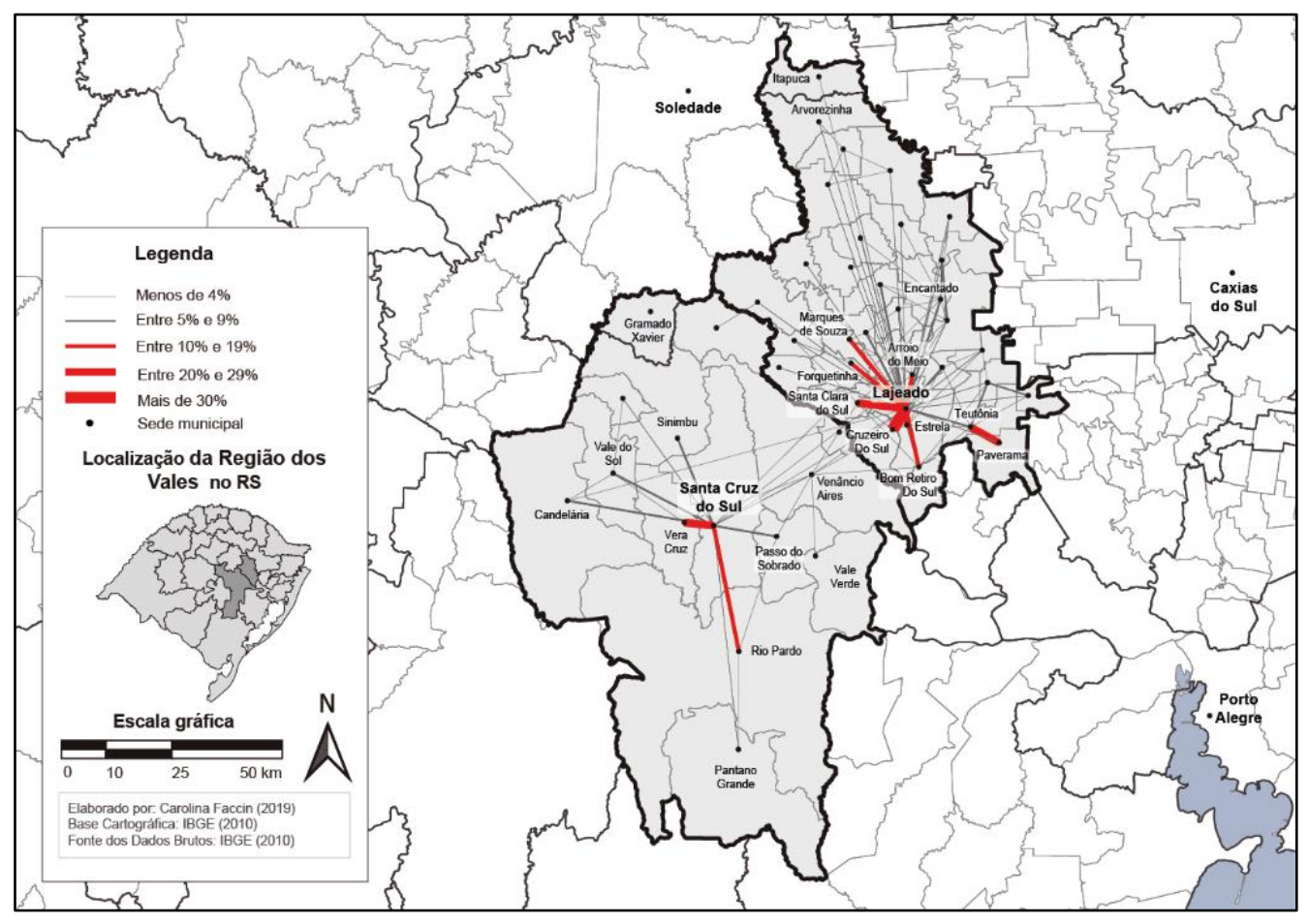

Fonte: Carolina Faccin, a partir de IBGE (2010). 
Destes fluxos, destacam-se aqueles com percentual superior a 10\%. Com direção à Santa Cruz do Sul, destacam-se os fluxos provenientes das cidades de Vera Cruz (19,57\%), Rio Pardo (17,56\%) e Sinimbu (6,27\%), e com direção à Lajeado, os fluxos de Cruzeiro do Sul (33,79\%), Santa Clara do Sul (21,89\%), Arroio do Meio (17,90\%), Forquetinha (15,49\%), Marques de Souza (13,51\%) e Bom Retiro do Sul (12,02\%). Há também o expressivo deslocamento pendular de $22,43 \%$ de Paverama com direção a Teutônia. Os dados se apresentam de forma desigual no território, em função da localização espacial e da proximidade entre local de origem e de destino. Bem como, em razão das diferentes condições de atração das cidades, que se alteram de acordo com o tamanho do núcleo urbano, e da diversificação de sua economia urbana e estrutura de serviços (IBGE, 2010).

Pode-se observar que as cidades de Santa Cruz do Sul e Lajeado, principais núcleos urbanos regionais, atraem a maior parte dos fluxos pendulares do conjunto dos municípios da região, evidenciando suas posições como centros de comando da rede urbana regional e a centralidade de suas economias urbanas na Região dos Vales. Além disso, em ambas as regiões a configuração espacial dos fluxos pendulares se concentram sobre tudo nas áreas centrais das suas REGICs. Também se destacam os deslocamentos que ocorrem com destino para os centros de zona A, Venâncio Aires e Encantado e os centros de zona B, Arvorezinha, Sinimbu, Teutônia, Arroio do Meio e Muçum.

Através dos dados do Censo Demográfico do IBGE de 2010, relativos à taxa líquida de migração existente entre 2005 e 2010, no âmbito da REGIC de Santa Cruz do Sul, somente cinco, dos 14 municípios, atingiram uma taxa positiva, sendo as maiores a de Mato Leitão (10,65\%), Passo do Sobrado (4,60\%) e Vera Cruz (4,13\%). De outro lado, nove municípios possuem taxas negativas, dentre eles destacam-se as de Herveiras (6,92\%), Rio Pardo (-4,78\%) e Gramado Xavier (-4,07\%). Além disso, os municípios que integram a rede urbana dessa REGIC apresentam uma média negativa de -1,09\%, o que indica que a rede urbana regional, bem como a maior parte de seus municípios, está tendo uma perda de sua população (IBGE, 2010). A figura 4 ilustra bem essa dinâmica migratória.

Já na REGIC de Lajeado, 19 dos 33 municípios possuíam taxa líquida de migração positiva, podendo destacar os municípios de Teutônia, com 10,19\%, Westfália, com 8,13\% e Roca Sales, com 7,05\%. Entre os 14 municípios restantes, que totalizaram taxas negativas, destacam-se Canudos do Vale $(-7,12 \%)$, Nova Bréscia (5,58\%), Putinga (-5,56\%) e Arvorezinha (-5,21\%). Quanto à média regional, apresentou-se uma taxa positiva de 0,58\%. Assim, e tendo em vista que a maior parte de seus municípios atingiu uma taxa positiva, pode-se dizer que, de modo geral, a região está recebendo população (IBGE, 2010). 
Figura 4. Taxa líquida de migração municipal nas regiões de influência de Santa Cruz do Sul e Lajeado, entre 2005 e 2010.

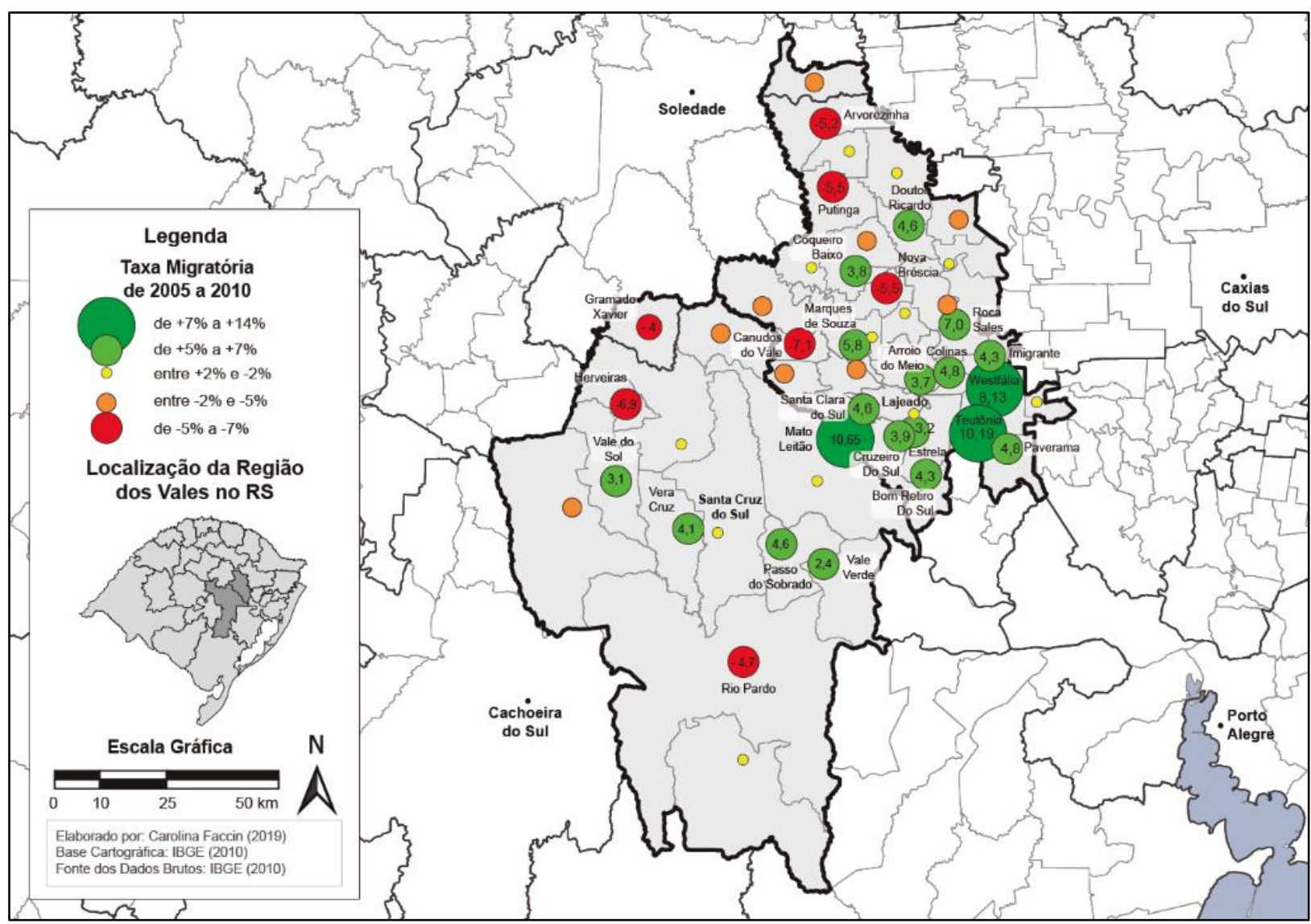

Fonte: Carolina Faccin, a partir de IBGE (2010).

Além disso, as maiores taxas líquidas de migração de ambas as regiões não se concentram nos municípios com maior população. De um lado, Santa Cruz do Sul atingiu a taxa de $-0,82 \%$, Venâncio Aires a de 0,24\% e Lajeado a de 1,18\%. De outro lado, Mato Leitão atingiu a de 10,65\% e Westfália, 8,13\%, ambos os municípios com menos de cinco mil habitantes. Também se destaca Teutônia, com 27.272 habitantes, e taxa positiva de 10,19\%. Entretanto, há também municípios de pequeno porte com taxas negativas elevadas, como Canudos do Vale (-7,12\%) e Herveiras (-6,92\%) (IBGE, 2010).

Com relação aos dados de crescimento populacional no período de 2000 a 2010, a Figura 5 apresenta a representação dos dados no espaço geográfico. Na REGIC de Santa Cruz do Sul, percebe-se que, dos 14 municípios, apenas cinco apresentam taxa negativa, sendo entre -0,1\% e -2\%, com exceção de Pântano Grande, que apresentou um decréscimo populacional de $-10 \%$. Entre os percentuais mais altos, estão os municípios de Mato Leitão (20\%), Vera Cruz (13\%) e Santa Cruz do Sul (10\%). Por fim, a média regional foi positiva, com 6\% de crescimento.

Por outro lado, a REGIC de Lajeado apresenta valores desiguais. Dos 33 municípios, 15 apresentaram crescimento negativo e 13 apresentaram crescimento positivo. Ainda, para cinco municípios não há dados de crescimento, já que a emancipação municipal ocorreu após o Censo Demográfico de 2000 e, logo, não possuem dados relativos ao número de habitantes no ano de 2000. As menores taxas de crescimento populacional (negativas) encontram-se nos municípios de Nova Bréscia (-30\%), Imigrante (-21\%), Sério (-16\%), Pouso Novo (- 
15\%), Itapuca (-13\%), Vespasiano Correa (-11\%) e Putinga (-11\%), sendo estes municípios com população inferior a cinco mil habitantes. Já, entre as maiores taxas, destacam-se os municípios com maior concentração populacional da região. São estes: Teutônia (19\%), Santa Clara do Sul (19\%), Estrela (12\%), Roca Sales (11\%), Lajeado (11\%), Encantado (11\%) e Arroio do Meio (11\%). A região totaliza, de modo geral, uma média de $10 \%$ de crescimento populacional positivo entre 2000 e 2010.

Figura 5. Taxa de crescimento populacional municipal nas regiões de influência de Santa Cruz do Sul e Lajeado, entre 2000 e 2010.

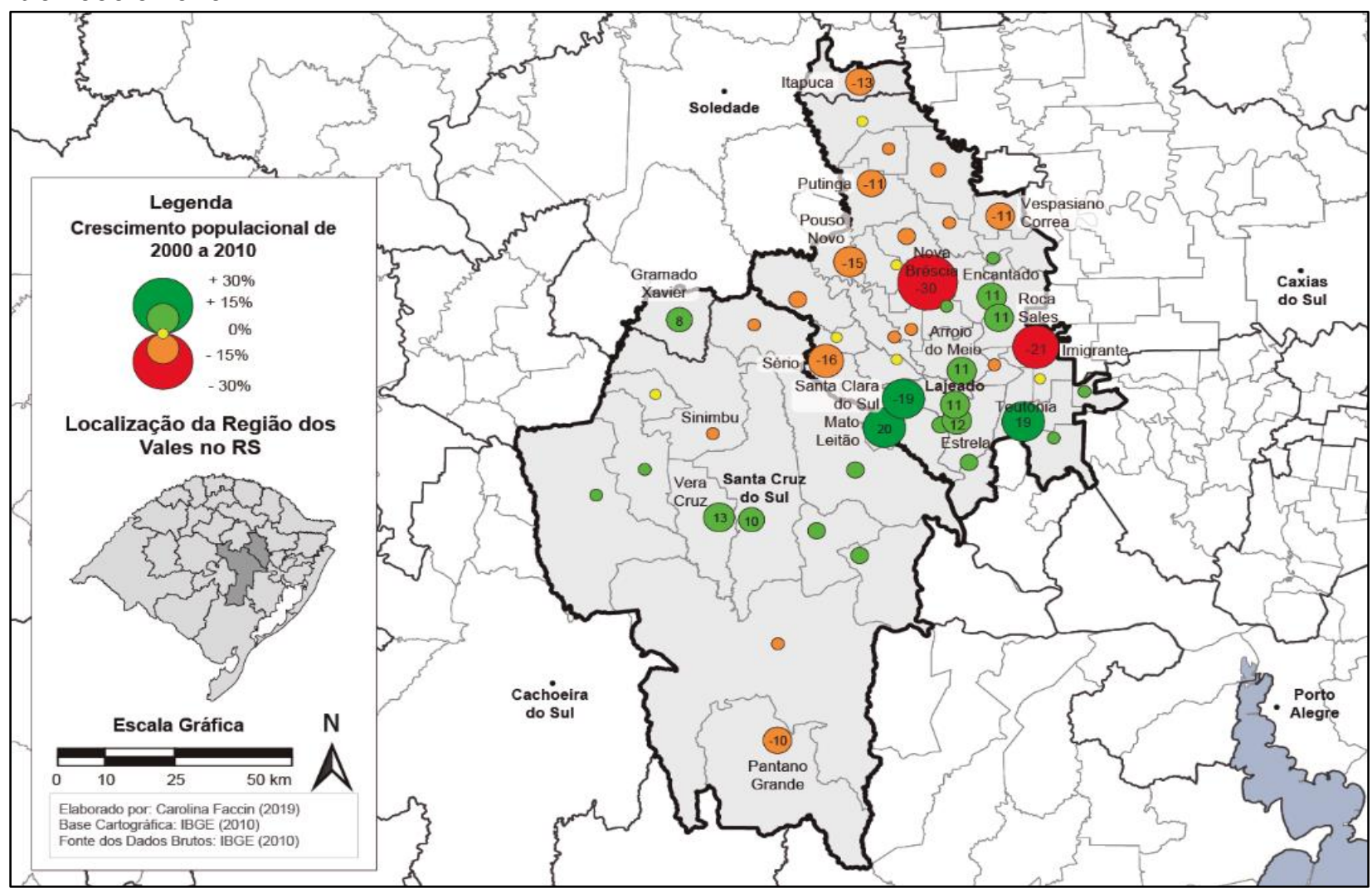

Fonte: Carolina Faccin, a partir de IBGE (2010) e IBGE (2000).

Quanto à situação de equilíbrio, em relação ao crescimento populacional entre os municípios da região, nos períodos de 1991 a 2000 e de 2000 a 2010, a Figura 6 apresenta a representação espacial dessa dinâmica demográfica. Para isso, utilizou-se da metodologia elaborada por Ramos, Matos e Garcia (2011, p. 48-47):

\footnotetext{
Os municípios são classificados em três grupos a fim de se perceber a consistência de seu crescimento demográfico. Os municípios que receberam a denominação negativo (vermelho) foram aqueles que apresentaram taxas de crescimento negativas nos dois períodos; os que são classificados como inconsistentes (amarelo) foram aqueles que mostraram crescimento positivo em apenas um período, sendo o outro negativo; os que apresentam a denominação positivo (verde) foram os que mostraram consistência, com taxas de crescimento positivas nos dois períodos.
}

Tendo isso em vista e a partir da análise da Figura 6, nota-se que, na REGIC de Santa Cruz do Sul, dos 14 municípios, oito estão em situação de crescimento consistente (ou seja, com crescimento positivo nos dois períodos, de 1991 a 2000 e de 2000 a 2010), dois em situação de crescimento negativa e o restante (quatro) com crescimento inconsistente. Já na REGIC de Lajeado, dos 33 municípios, apenas nove estão em situação de crescimento consistente, 15 em crescimento negativo e o restante (nove) em crescimento inconsistente. Desse 
modo, em ambas as redes urbanas, tanto na de Santa Cruz do Sul, quanto na de Lajeado, evidencia-se uma situação de crescimento desequilibrado.

Figura 6. Situação de equilíbrio com relação ao crescimento populacional (1991-2000) e (2000-2010).

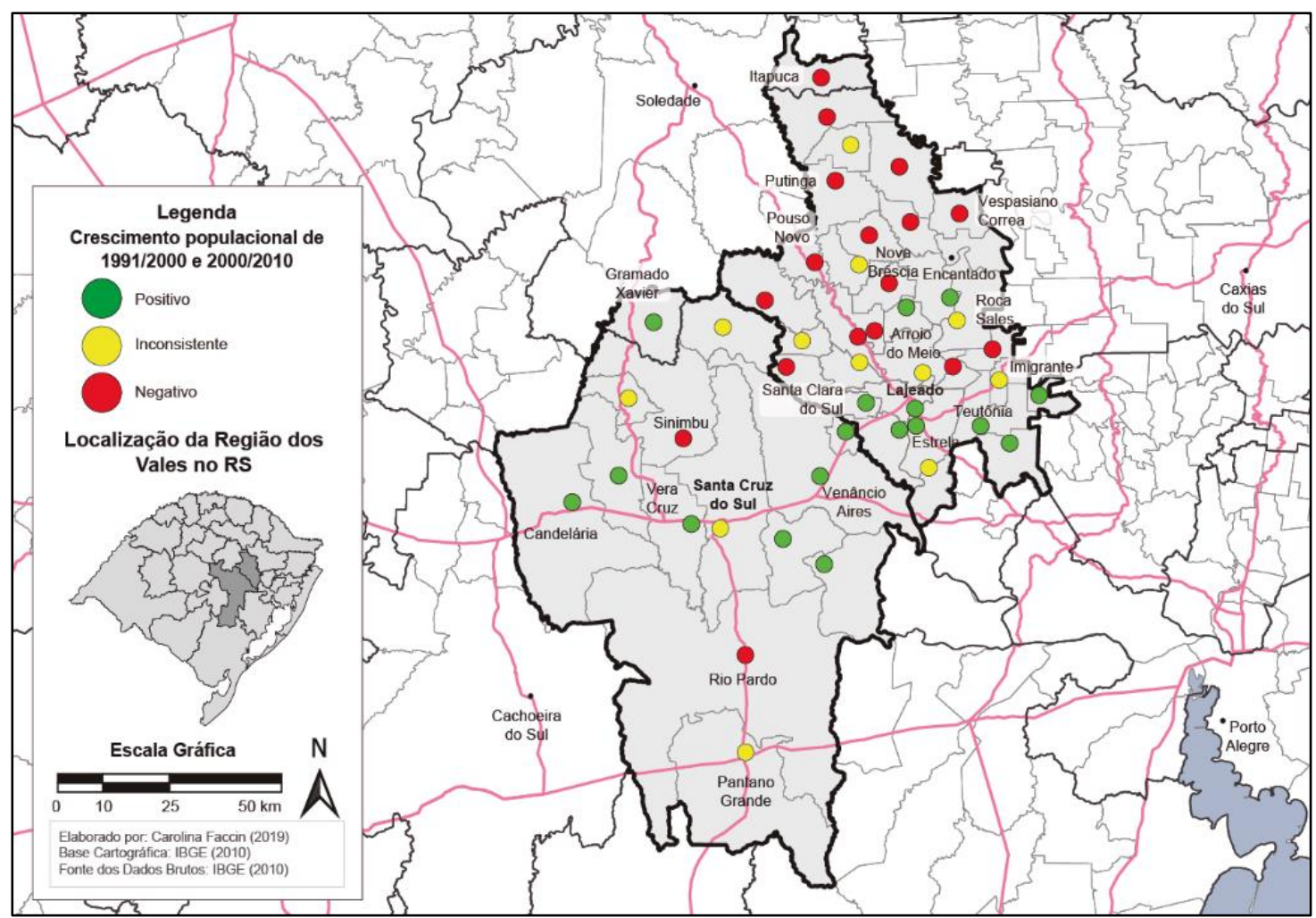

Fonte: Carolina Faccin, a partir de IBGE (2010).

Além disso, de modo geral, os municípios com as maiores concentrações populacionais, apresentaram as maiores taxas de crescimento. As exceções se deram na região de influência de Santa Cruz do Sul, para dois municípios. 0 primeiro, Santa Cruz do Sul, município com a maior concentração populacional de toda a Região dos Vales, foi classificada como inconsistente devido a uma redução de $-9 \%$ no seu número de habitantes no período de 1991 a 2000. Isso se deu graças à emancipação dos municípios de Vale do Sol, Sinimbu e Herveiras, entre 1992 e 1995, resultando na diminuição da área territorial e na consequente diminuição da população do município, principalmente da população rural. Quanto à Rio Pardo, terceiro município com o maior contingente populacional da região, contava com 37.591 habitantes em 2010, vem progressivamente sofrendo uma redução de sua população, seja também pelas emancipações de Vale Verde, Passo do Sobrado, seja pela anexação do distrito de São José da Reserva à Santa Cruz do Sul e/ou seja, pela perda de dinamismo de sua economia urbana.

A estrutura viária, também representada na Figura 2 e na Figura 6, por sua vez, também contribui e condiciona a dinâmica de relações entre as cidades na rede urbana. Sua estrutura é deficiente quanto à abrangência e à qualidade do sistema viário. Basicamente, tem-se uma rede de estradas de rodagem cuja distribuição espacial é desigual no território. A maior densidade da malha rodoviária federal e estadual, asfaltada, está concentrada na zona central da REGIC de Santa Cruz do Sul e na parte sul da REGIC de Lajeado, mais próxima à Região Metropolitana de Porto Alegre. Nesse sentido, percebe-se que a maior parte dos 
municípios com crescimento populacional positivo nos dois períodos avaliados localizam-se próximos aos principais eixos rodoviários.

Quanto à análise do PIB, verificou-se que, tanto na região de influência de Santa Cruz do Sul, quanto na de Lajeado, vem ocorrendo uma evolução econômica em todos os municípios, já que nenhum deles apresentou crescimento do PIB negativo entre 2000 e 2010. Na REGIC de Santa Cruz do Sul, a média regional do crescimento do PIB foi de 18,4\% ao ano, entre 2000 e 2010. Sinimbu apresentou o menor crescimento ao ano, de 11,4\%, enquanto Mato Leitão e Vale do Sol apresentaram igualmente um crescimento de 31,2\% ao ano. Já na REGIC de Lajeado a média regional do crescimento do PIB foi de 19,4\% a.a. Com as menores taxas de crescimento da região, entre 2000 e 2010, destaca-se os municípios de Teutônia (5,7\% a.a.) e Roca Sales (7,1\% a.a.). Já os com as maiores taxas de crescimento, em destaque estão os municípios de Muçum (57,6\% a.a.) e Imigrante (45,4\% a.a.) (IBGE, 2016b).

Apesar de manterem uma taxa de crescimento estável, ambas as regiões apresentam uma distribuição bastante desigual da riqueza produzida entre os municípios que a integram. Na REGIC de Santa Cruz do Sul, com relação ao PIB per capita, em 2010, destacam-se com os maiores desempenhos, os municípios de Santa Cruz do Sul (R\$ 33.326), Venâncio Aires (R\$ 26.140) e Mato Leitão (R\$ 24.665). Esses três municípios, inclusive, ultrapassam a média nacional (R\$ 19.878) e a média estadual (R\$ 22.557) (Tabela 3). Já, com o menor PIB per capita, destacam-se os municípios de Gramado Xavier (R\$ 9.972) e Boqueirão do Leão (R\$ 10.341) (IBGE, 2016b).

Já em relação ao PIB a preços correntes, continuam-se destacando os municípios mais populosos da região, Santa Cruz do Sul (R\$ 4.178.595) e Venâncio Aires (R\$ 1.724.270), com os valores mais altos. É possível perceber uma intensa concentração econômica por parte desses dois municípios, já que a soma de seus PIBs configura $74 \%$ do total do PIB regional. Tal desempenho é explicado em parte pela força da atividade industrial do tabaco nesses dois municípios, que responde pela maior parte dos recursos gerados. Já com os mais baixos PIBs, estão Herveiras (R\$ 39.590) e Gramado Xavier (R\$ 39.590). Por fim, nota-se também que o PIB da REGIC de Santa Cruz do Sul, em termos absolutos (7.972.157 bilhões de reais), é o maior entre as duas REGICs analisadas, apesar de conter o menor número de municípios (Tabela 4) (IBGE, 2016b).

Tabela 4. Produto Interno Bruto - PIB (2010).

\begin{tabular}{ccc}
\hline $\begin{array}{c}\text { Grandes Regiões, } \\
\text { Unidades da Federação } \\
\text { e Municípios }\end{array}$ & $\begin{array}{c}\text { A preços correntes } \\
\mathbf{( 1 ~ 0 0 0 ~} \mathbf{\$} \mathbf{)}\end{array}$ & $\begin{array}{c}\text { Per capita } \\
\mathbf{( R \boldsymbol { \$ } )}\end{array}$ \\
\hline REGIC Lajeado & 6.609 .603 & 17.766 \\
\hline REGIC Santa Cruz do Sul & 7.972 .157 & 16.584 \\
\hline Rio Grande do Sul & 241.255 .555 & 22.557 \\
\hline Sul & 620.196 .524 & 22.647 \\
\hline Brasil & 3.885 .847 .000 & 19.878 \\
\hline
\end{tabular}

Fonte: Carolina Faccin, a partir de IBGE (2016b).

A REGIC de Lajeado, assim como a de Santa Cruz do Sul, também apresenta uma desigual distribuição da riqueza entre os municípios que a integram. Com relação ao PIB per capita, pode-se destacar os municípios com os maiores PIBs: Muçum (R\$ 39.177), Imigrante (R\$ 36.366) e Lajeado (R $\$ 29.718)$, ultrapassando as médias da região, do estado e do país. E os com menores PIBs per capita: Paverama (R\$ 10.861), Progresso (R\$ 11.091) e Sério (R\$11.014). Observa-se que os municípios mais populosos da região não se destacam como os com maiores PIBs per capita. Isso não acontece, no entanto, quando se volta o olhar para os dados referentes ao 
PIB a preços correntes, nos quais se destacam os municípios de Lajeado, Estrela, Teutônia, Arroio do Meio e Encantado com os maiores PIBs. A soma do PIB destes cinco municípios totaliza $70,5 \%$ do total do PIB da região. Já, com os menores PIBs, entre R\$ 21.373 e R\$ 30.744, estão Coqueiro Baixo, Canudos do Vale, Sério, Poço das Antas, Pouso Novo, Itapuca, Relvado e Doutor Ricardo (IBGE, 2016b).

\section{CONSIDERAÇÕES FINAIS}

Estes resultados evidenciam a importância das cidades médias de Santa Cruz do Sul e Lajeado na rede urbana regional, ambas com os PIBs mais elevados da região. Além disso, as duas regiões de influência apresentaram evolução positiva, principalmente se considerada a variável PIB, apesar de uma desigual distribuição da riqueza produzida entre os municípios que as integram. Apesar disso, a análise do PIB nos permite perceber uma evolução econômica positiva nos municípios de ambas REGICs, entre os anos 2000 e 2010, já que as médias de crescimento do PIB na região foram altas nesse período avaliado, bem como houve um crescimento positivo em todos os municípios integrantes das regiões.

Os dados relativos aos percentuais de deslocamento pendular da PEA, para trabalho e estudo, destacam as cidades médias de Santa Cruz do Sul e Lajeado. Os fluxos mais dinâmicos e intensos têm se concentrado, sobretudo nas áreas centrais de cada uma das REGICs, onde estão localizadas as cidades médias de Santa Cruz do Sul e Lajeado reforçando o dinamismo desse segmento espacial da rede urbana regional. Destaca-se também a cidade de Teutônia, que polariza os fluxos do município de Paverama com 22,43\% de deslocamento da PEA. Também pode-se destacar, em menor grau, os municípios de Venâncio Aires, que polariza os municípios de seu entorno, e principalmente Mato Leitão, bem como Encantado, polarizando os municípios de seu entorno.

Já os dados relativos à taxa de crescimento populacional e à taxa liquida migratória apresentam uma grande disparidade municipal, principalmente entre os municípios da REGIC de Lajeado. Verifica-se um expressivo crescimento populacional e taxa de migração líquida positiva nos municípios ao centro-sul da REGIC de Lajeado, e em alguns do centro da REGIC de Santa Cruz do Sul. Principalmente, naqueles em que predominam as atividades associadas ao setor de serviços e possuem maior parte da população residente de área urbana. Por outro lado, constatou-se uma diminuição no crescimento populacional e taxa de migração líquida negativa em outros municípios, principalmente naqueles em que predomina a população rural e que prevalecem as atividades associadas ao setor da agropecuária.

A REGIC de Santa Cruz do Sul apresenta uma média negativa de $-1,09 \%$, quanto à taxa líquida de migração regional, o que indica que a rede urbana, bem como a maior parte de seus municípios, está tendo uma perda de sua população. Já a REGIC de Lajeado, apresenta uma taxa líquida de migração positiva de $0,58 \%$ quanto à média regional. Assim e, tendo em vista que a maior parte de seus municípios atingiu uma taxa positiva, pode-se dizer que, de modo geral, a região está recebendo população.

Os dados do PIB confirmam o demonstrado através dos dados demográficos: há de fato uma maior concentração econômica e populacional nos municípios mais populosos. Deve-se lembrar também, no entanto, de que todos os municípios das REGICs apresentaram taxas de crescimento positivas no período entre 2000 e 2010, o que permite afirmar que os municípios-polos atraem investimentos para a rede como um todo e não apenas para si, apesar de ainda concentrarem a maioria. Além disso, é importante destacar que os municípios das regiões podem estar recebendo também investimentos de outros polos próximos que não apenas das REGICs de Santa Cruz do Sul e Lajeado. 
A partir da análise dos dados representados nos mapas temáticos, também pode-se observar que nas duas REGICs, os municípios que apresentaram maior e mais consistente crescimento populacional, ou ainda mais elevada taxa migratória, foram os que tinham uma localização geográfica mais favorável, no centro da REGIC, com proximidade a eixos viários que os liga à metrópole e capital gaúcha, Porto Alegre, aos centros regionais de Caxias do Sul ou de Santa Maria. Além disso, os municípios polos de Santa Cruz do Sul e Lajeado tiveram importante peso no desenvolvimento da rede, por concentrarem boa parte da população e do PIB, além de apresentarem taxas elevadas de crescimento. Constata-se, enfim, que os municípios polos têm uma expressiva importância em suas respectivas REGICs.

Enfim, entende-se também que o estudo da rede urbana é essencial para se compreender as relações econômicas, de dependência e de articulação interna e externa ao país. Por conta disso, tal estudo é considerado importante na formulação de diagnósticos e proposições de políticas, planos e programas. Seja em nível regional, estadual e nacional.

Destaca-se também o caráter sistêmico da relação entre cidades. Entende-se que nos isolados, ou centros urbanos analisados de forma individual, sem o respectivo contexto da rede urbana em que estão inseridos, não serão interpretados em toda a sua complexidade, no tocante a suas relações econômicas, políticas e sociais.

Além disso, os centros com população urbana superior a 50 mil habitantes são fundamentais na organização da rede urbana do Rio Grande do Sul. Muitos deles se aglutinam nos espaços das aglomerações urbanas e metropolitanas, mas o arranjo espacial, ao longo das décadas, reforça também a importância de poucos centros isolados, hoje correspondendo exatamente aos polos regionais e sub-regionais consolidados do interior, como é o caso das cidades de Santa Cruz do Sul e Lajeado.

Por fim, pensa-se que o uso metodológico e operacional dos conceitos de cidade média e rede urbana mostram-se relevantes para melhor compreender a dinâmica territorial e pensar estratégias de desenvolvimento na escala regional. Tendo em visa que oportunizam uma melhor observação e compreensão do conteúdo, das características, das orientações e relações dos fluxos, como os de pessoas, que através do movimento pendular e migração, circulam e conectam não apenas as cidades, mas também os demais espaços do território, em diferentes níveis escalares.

Contudo, os resultados ainda parciais desse estudo não permitem compreender, em profundidade, o papel de centralidade das cidades médias na dinâmica regional, a própria dinâmica de desenvolvimento regional, e a organização e funcionamento da rede urbana regional. Para tanto, ainda será preciso concluir os demais estudos, já iniciados no âmbito do projeto de pesquisa, sobre os demais fluxos que circulam no interior das áreas urbanas funcionais e da região, como os fluxos de capital, de mercadorias, produtos e informações para melhor analisar e compreender as conexões e interrelações existentes na dinâmica de desenvolvimento territorial na região dos Vales.

\section{REFERÊNCIAS}

ANDRADE, T. A.; SERRA, R. V. 0 recente desempenho das cidades médias no crescimento populacional urbano brasileiro. Rio de Janeiro: IPEA, 1998 (Texto para Discussão, 554).

ARRAIS, Tadeu Alencar. A cidade e a região/a cidade-região: reconhecer processos, construir políticas. Revista Cadernos Metrópole, n. 20, p. 81-91, $2^{\circ}$ sem, 2008. 
BRANCO, Maria Luisa Castello. As cidades médias no Brasil. In: SPÓSITO, Eliseu Savério; SPÓSITO, Maria Encarnação Beltrão; SOBARZO, Oscar. (Orgs.). Cidades médias: produção do espaço urbano regional. São Paulo: Expressão Popular, 2006. p. 245-277.

CATTAN, Nadine. (2007). (Org.) Cities and networks in Europe: a critical approach of polycentrism. Montrouge, France: John Libbey Eurotext.

CORRÊA, Roberto Lobato. A rede urbana. São Paulo: Editora Ática, 1989.

Estudos sobre a rede urbana. Rio de Janeiro: Ed. Bertrand Brasil. 2006.

A rede urbana e a cidade média. p. 29-38. In: SILVA, W. R.; SPOSITO, M. E. Perspectivas da urbanização: reestruturação urbana e das cidades. Rio de Janeiro: Consequência Editora, 2017. 1. ed. 270 p.

DAVOUDI, S. Polycentricity in European Spatial Planning: From an Analytical Tool to a Normative Agenda. European Planning Studies, v.11, n.8, December, p.979-999, 2003.

DEUS, João Batista. As cidades médias na nova configuração territorial brasileira. Boletim Goiano de Geografia, Goiânia, v. 24, n. 1-2, p. 81-91. jan./jun. 2004.

ESPON. ESPON 111. Potentials for polycentric development in Europe. Project report. August, 2004. Disponível em:

<https://www.espon.eu/export/sites/default/Documents/Projects/ESPON2006Projects/ThematicProjects/Polyc entricity/fr-1.1.1_revised-full.pdf>. Acesso em: 11 abr. 2017.

FONSECA, F. P.; RAMOS, R. A. R. Formas de cooperação interurbana: o caso da rede de cidades do quadrilátero urbano. Revista Portuguesa de Estudos Regionais, Portugal, n. 25-26, p. 37-54. 2011.

IBGE (Instituto Brasileiro de Geografia e Estatística). Censo Demográfico: 1991: resultados do universo relativos as características da população e dos domicílios. Rio de Janeiro: IBGE, 1991. Disponível em: <https://biblioteca.ibge.gov.br/biblioteca-catalogo?id=782>. Acesso em 15 fev. 2019.

Censo Demográfico: 2000: . Rio de Janeiro: IBGE, 2000. Disponível em:

<https://biblioteca.ibge.gov.br/pt/biblioteca-catalogo?view=detalhes\&id=783>. Acesso em 15 fev. 2019.

Regiões de Influência das Cidades. Rio de Janeiro: IBGE, 2008. Disponível em:

<https://biblioteca.ibge.gov.br/visualizacao/livros/liv40677.pdf>. Acesso em: 10 dez. 2017.

. Censo Demográfico do Brasil: 2010. Rio de Janeiro: IBGE, 2010. Disponível em:

<http://www.ibge.gov.br/home/estatistica/populacao/censo2010/ >. Acesso em: 11 abr. 2017.

. Grade Estatística. Rio de Janeiro: IBGE, 2016a. Disponível:

<https://mapas.ibge.gov.br/interativos/grade>. Acesso em: 10 dez. 2017.

Sistema IBGE de Recuperação Automática (SIDRA) - Produto Interno Bruto dos Municípios: Tabela 5938. 2016b. Disponível em: <https://sidra.ibge.gov.br/tabela/5938>. Acesso em 15 fev. 2019.

Estimativa Populacional 2018. Disponível em: <https://www.ibge.gov.br/estatisticasnovoportal/sociais/populacao/9103-estimativas-de-populacao.html?=\&t=resultados>. Acesso em 21 set. 2018. OLIVEIRA, H. C. M. de; SOARES, B. R. Cidade média: apontamentos metodológicos e tipologia. Caminhos de Geografia, Uberlândia, v. 15, n. 1, p. 119-133, dez. 2014.

PILLET, F. et al. El policentrismo em Castilla-La Mancha y su análisis a partir de la población vinculada y el crecimiento demográfico. Scripta Nova. Revista Electrónica de Geografía y Ciencias Sociales. Barcelona: Universidad de Barcelona, 20 abr. 2010, v. XIV, n. 321.

RODRIGUES, M. J.; SILVA, F. B. Considerações teóricas sobre rede urbana. Revista Eletrônica do Curso de Geografia do Campus de Jataí. Jataí, n. 8, jan./jun. 2007.

RAMOS, E. F.; MATOS, R. E. S.; GARCIA, R. A. As cidades médias como nódulos de equilíbrio da rede de cidades. Revista Paranaense de Desenvolvimento, Curitiba, n. 121, p. 41-63, jul./dez. 2011. 
SANFELIU, Carmen Bellet. Las ciudades intermedias en los tiempos de la globalización. In: LLOP, J. M.; USÓN, E. Ciudades intermedias: dimensiones y definiciones. Lleida: Editorial Milenio, 2012. p. 222-249.

SEPLAN (Secretaria do Planejamento, Mobilidade e Desenvolvimento Regional). Perfis Socioeconômicos por Regiões Funcionais de Planejamento. p. 25-30. Porto Alegre: SEPLAN, 2015. Disponível em:

<http://planejamento.rs.gov.br/upload/arquivos/201512/15134058-20150319163519perfis-todos.pdf>. Acesso em: 10 dez. 2017.

SILVEIRA, Rogério Leandro Lima da. Território, redes e desenvolvimento regional: notas para discussão. SILVEIRA, R. L. L. da S. e FELIPPI, A. C. T. (Orgs.). Territórios, redes e desenvolvimento regional: perspectivas e desafios. Florianópolis: Insular, 2018.

SOARES, Beatriz Ribeiro. Cidades médias: uma revisão bibliográfica. In: ALVES, A. F.; FLÁVIO, L. C.; SANTOS, R. A. (Org.). Espaço e território: interpretações e perspectivas do desenvolvimento. Francisco Beltrão: UNIOESTE, 2005. p. 273-285.

STAMM, C. et al. A população urbana e a difusão das cidades de porte médio no Brasil. INTERAÇÕES, Campo Grande, v. 14, n. 2, p. 251-265, jul./dez. 2013.

SÝKORA, L.; MULÍČEK, O. The micro-regional nature of functional urban areas (FUAs): lessons from the analysis of the Czech urban and regional system. Urban Research \& Practice. v. 2, n. 3, p. 287-307, 2009. 